\title{
Production of human chorionic gonadotrophin by a hepatoblastoma resulting in precocious puberty
}

\author{
RICHARD BEACH, PETER BETTS, MARTIN RADFORD, HARRY MILLWARD-SADLER
}

From the Departments of Paediatrics and Histopathology, Southampton General Hospital, Southampton SO9 $4 X Y$

SUMMARY A two year old boy presented with precocious puberty associated with hepatoblastoma. Serum concentrations of $\beta$ human chorionic gonadotrophin and $\alpha$-fetoprotein were raised. An aggressive chemotherapeutic regimen resulted in useful palliation and interesting changes in the $\beta$ human chorionic gonadotrophin and $\alpha$-fetoprotein concentrations. In contrast to a previous report, the ultrastructure of the tumour showed frequent Golgi apparatus but no other electron dense membrane bound vesicles.

Hepatoblastoma is an embryonal tumour which can be associated with various non-metastatic syndromes. $\alpha$-fetoprotein or, rarely, human chorionic gonadotrophin may be produced by the tumour and may be used as a tumour marker. Ectopic gonadotrophin production from this source is a rare cause of precocious puberty in boys.

\section{Case report}

PRESENTING FEATURES

A boy aged 28 months presented with a four month history of rapid skeletal growth, increasing penile size, pubic hair, and deepening of the voice. Examination showed him to be on the 90th percentile for height and weight and to have oily skin, a deep voice, pubic hair (stage II), and genital development (stage IV).' However, both testes were small (Prader Beads $3 \mathrm{ml}$ ). There was a large, firm, irregular hepatic mass extending down to the level of the umbilicus.

\section{MANAGEMENT}

Liver imaging using both ultrasound and radionucleotide scanning showed a mass $8 \mathrm{~cm}$ in diameter within the right lobe of the liver. At laparotomy the tumour was found to extend across into the left lobe of the liver and was considered inoperable. Needle biopsy samples of the tumour were taken. There was no evidence on clinical examination, chest radiograph, and bone scan or at laparotomy for the spread of the tumour beyond the liver.

Accepted for publication 30 March 1984

\section{LABORATORY INVESTIGATIONS}

Results of laboratory investigations were as follows: haemoglobin concentration $8.8 \mathrm{~g} / \mathrm{dl}$; erythrocyte sedimentation rate $38 \mathrm{~mm}$ in the first hour; serum bilirubin and liver transaminase values normal; plasma alkaline phosphatase $>2000 \mathrm{IU} / \mathrm{l}$; serum $\beta$ human chorionic gonadotrophin concentration 197 IU/l (normal <5 IU/l); $\alpha$-fetoprotein concentration $404 \times 10^{3} \mathrm{KU} / 1$ (normal <5KU/l); plasma testosterone $49 \mathrm{nmol} / 1$ (normal for adult male $<30 \mathrm{nmol} /$ 1); plasma oestradiol $520 \mathrm{pmol} / \mathrm{l}$ (adult males $<160$ pmol/l); basal plasma follicle stimulating hormone concentration $2 \mathrm{IU} / \mathrm{l}$ with no rise on luteinising hormone releasing hormone stimulation; basal luteinising hormone concentration $41 \mathrm{IU} / \mathrm{l}$ (owing to a cross reactivity with $\beta$ human chorionic gonadotrophin).

\section{PATHOLOGY}

Light microscopy showed a vascular tumour arranged in a trabecular/sinusoidal pattern with numerous foci of haemopoiesis in the sinusoidal channels. The predominant tumour cell was large and polygonal and resembled fetal hepatocytes, but a few smaller, oval to polygonal cells with less cytoplasm resembling embryonal hepatocytes were also present (Fig. 1a). A mesenchymal stromal component to the tumour was not identified. Electron microscopy confirmed the foci of haemopoiesis. The large polygonal tumour cells had complex folded and interdigitated plasma membranes (Fig. 1b). Desmosomes were not seen but large numbers of microfilaments were prominent beneath the plasma membranes. Mitochondria were numerous and usually round. Abnormal circular and septal cristae 

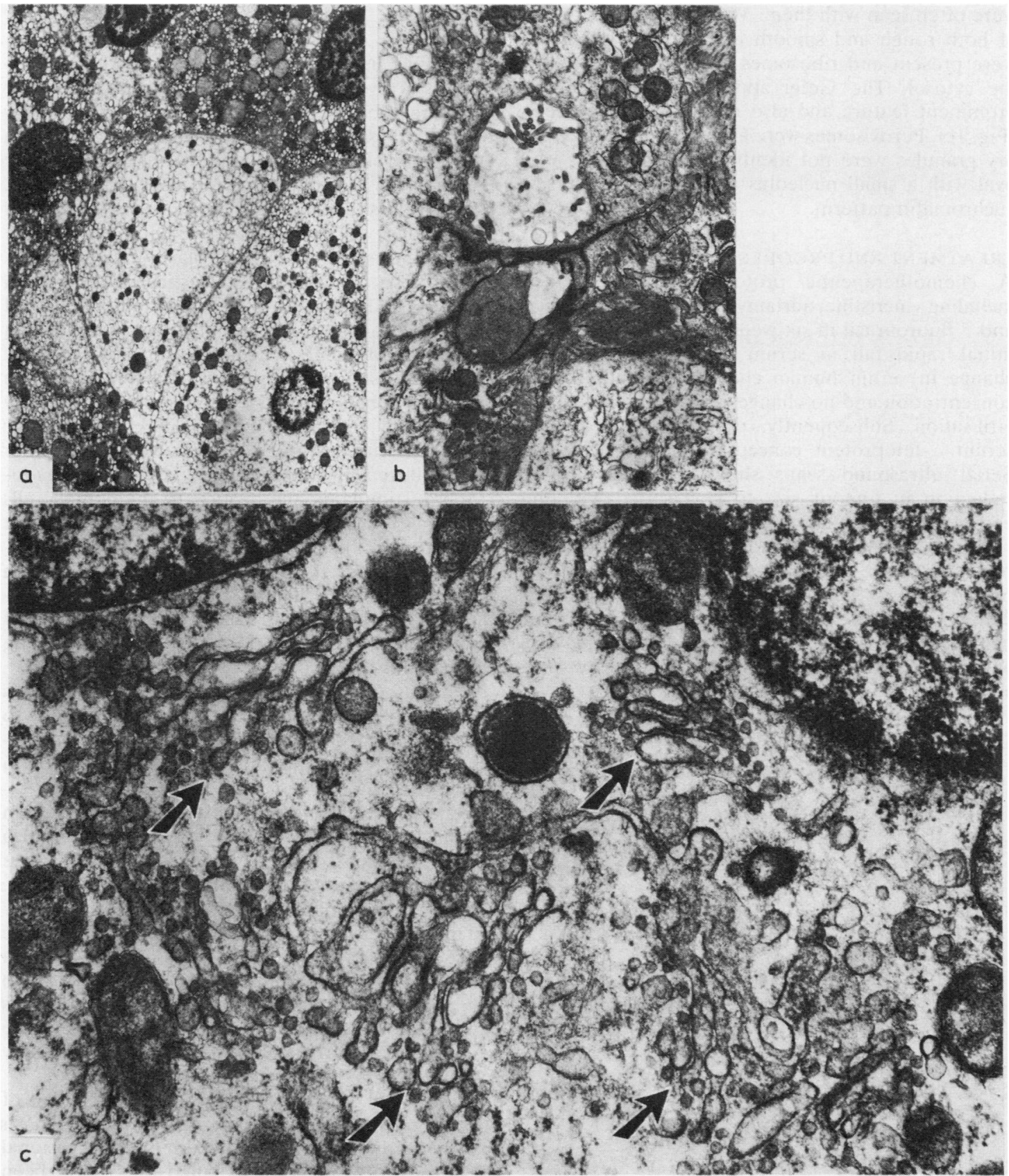

Fig. 1 (a) Tumour cells of two types are present. There are large cells with abundant cytoplasm, circular mitochondria widely dispersed among vesicular smooth endoplasmic reticulum, and a small nucleus (bottom right). Other tumour cells are smaller but have a relatively larger nucleus and greater numbers of mitochondria within the more electron dense cytoplasm. (uranyl acetate and lead citrate $\times 3200$ )

(b) There is pronounced complexity and infolding of the plasma membranes of the tumour cells. The cell top left has formed a large intracytoplasmic vacuole into which project several microvilli. (uranyl acetate and lead citrate $\times 8000$ )

(c) Portions of an infolded nucleus are seen top right and top left, a small membrane bound peroxisome 0.42 um diameter is present centre, and several sets of Golgi apparatus (arrows) surround the peroxisomes. There are numerous microfilaments and microtubules also present within the cytoplasm. (uranyl acetate and lead citrate. $\times 26000$ ) 
were often seen with them. Well developed profiles of both rough and smooth endoplasmic reticulum were present and ribosomes were also free within the cytosol. The Golgi apparatus was usually a prominent feature and also multiple in many cells (Fig. 1c). Peroxisomes were also present, but secretory granules were not identified. The nucleus was oval with a small nucleolus and a finely dispersed euchromatin pattern.

\section{TREATMENT AND PROGRESS}

A chemotherapeutic protocol was undertaken including vincristine, adriamycin, cyclophosphamide and 5 fluorouracil in six week cycles. There was an initial rapid fall in serum $\alpha$-fetoprotein but no change in serum human chorionic gonadotrophin concentration and no change in the clinical signs of virilisation. Subsequently, despite treatment, the serum $\alpha$-fetoprotein concentration rose (Fig. 2). Serial ultrasound scans showed no appreciable reduction in tumour size to correspond with the early fall in serum $\alpha$-fetoprotein concentration.

Treatment was well tolerated and the child remained active and in good health for $\mathbf{1 0}$ months from diagnosis. Subsequently, there was clinical evidence of local tumour growth with further hepatomegaly and jaundice. Chemotherapy was withdrawn and the child died 13 months after presentation.

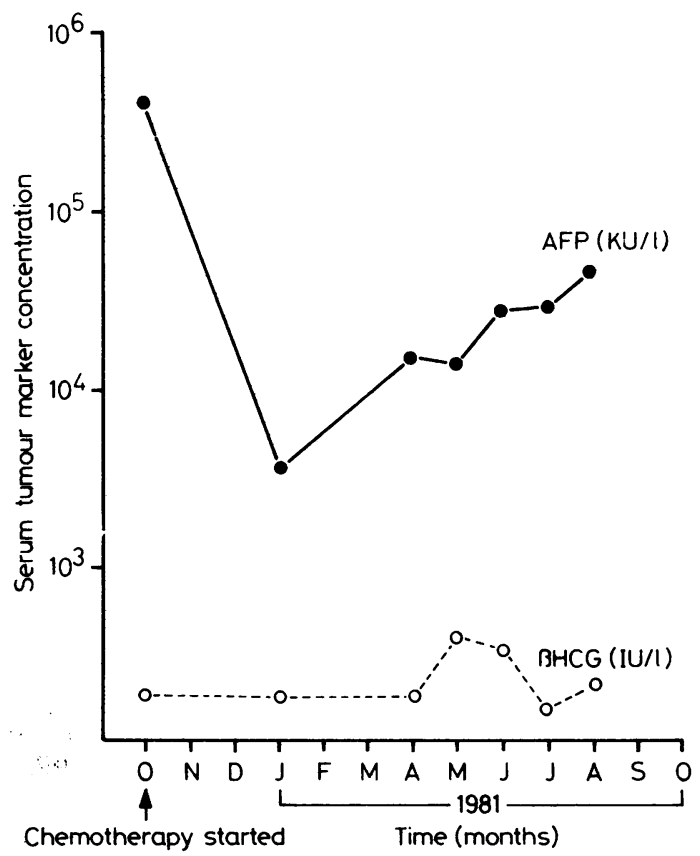

Fig. 2 Differential response of serum tumour markers to chemotherapy in a case of hepatoblastoma.

\section{Discussion}

Precocious puberty due to a virilising hepatoblastoma is a rare but well documented occurrence..$^{2-8}$ Cases have been confined to boys, generally below three years of age, who have usually presented with accelerated skeletal growth and virilisation. Hepatic enlargement at presentation has been invariable. Most authors report little or no increase in testicular size; biopsy samples, when taken, have usually shown interstitial cell hyperplasia but no spermatogenesis, which suggests testicular stimulation by a gonadotrophin with only interstitial cell stimulating activity. The circulating gonadotrophin which was originally detected by bioassay in early reports has subsequently been identified as human chorionic gonadotrophin using a radioimmunoassay specific for the $\beta$ chain. ${ }^{4}$ Human chorionic gonadotrophin has also been isolated from tumour cells cultured in vitro. ${ }^{4}$ Human chorionic gonadotrophin stimulates the testicular interstitial cells leading to androgen production and subsequent virilisation. Follicle stimulating hormone concentrations are unaltered-hence there is little increase in testicular size. The high circulating luteinising hormone concentrations are caused by cross reaction of human chorionic gonadotrophin in the luteinising hormone assay.

The raised plasma oestradiol concentration in this case and in previous reports ${ }^{368}$ was probably due to peripheral conversion of circulating androgens. Clinical evidence of feminisation has been restricted to gynaecomastia in one case. ${ }^{2}$

Raised concentrations of circulating $\alpha$-fetoprotein are not diagnostic of hepatoblastoma and are also found in hepatocellular carcinoma and some teratomas showing extra embryonal differentation. Circulating $\alpha$-fetoprotein concentrations offer a useful means of assessing response to treatment in some tumours. The differential response of human chorionic gonadotrophin and $\alpha$-fetoprotein to chemotherapy in this case, together with a previous similar report, ${ }^{3}$ suggests either synthesis by separate cell lines or differential sensitivity to chemotherapy of metabolic pathways in the same cell.

Long term survival is dependent on removal of the tumour; without surgical resection the prognosis is measured in months, although occasional responses to irradiation ${ }^{4}$ or vincristine ${ }^{10}$ have been recorded. Our aggressive use of chemotherapy apparently controlled the growth of this inoperable tumour for about nine months. A biochemical "response" to chemotherapy was noted with serum $\alpha$-fetoprotein concentration rapidly falling at the start of treatment. Circulating $\alpha$-fetoprotein concentrations may therefore provide an index of 
response to treatment in these tumours but must be interpreted cautiously since no similar fall in serum $\beta$ human chorionic gonadotrophin concentration occurred in our patient. None the less, as treatment was well tolerated and maintained the child in excellent general health, the chemotherapeutic regimen appears to have produced useful palliation in a surgically inoperable case.

In the only published report on the ultrastructural appearances of a virilising hepatoblastoma secretory granules were found within the tumour cell cytoplasm.' This is in contrast to our findings; tumour cells from our patient showed prominent and often multiple Golgi apparatus and, although peroxisomes and lysosomes were also present, there were no other membrane bound electron dense granules. As human chorionic gonadotrophin is a glycoprotein the presence of Golgi apparatus would be expected because this is required for addition of the carbohydrate side chains to the polypeptide. Conversely, secretory granules necessary for the storage of intermittently released cellular proteins would not be essential and, indeed, in our study were not present.

\section{References}

' Tanner JM. Growth and endocrinology in the adolescent. In:
Gardner L, ed. Endocrine and genetic diseases of childhood. Philadelphia: Saunders, 1969.

${ }^{2}$ Reeves RL, Tesluk H, Harrison CE. Precocious puberty associated with hepatoma. J Clin Endocrinol 1959;19:1651-9.

${ }^{3}$ Hung W, Blizzard RM, Migeon CJ, Camacho AM, Nyhan WL. Precocious puberty in a boy with hepatoma and circulating gonadotrophin. J Pediatr 1963;63:895-903.

4 Braunstein GD, Bridson WE, Glass A, Hull EW, McIntire KR. In vivo and in vitro production of human chorionic gonadotrophin and alpha-fetoprotein by a virilizing hepatoblastoma. $J$ Clin Endocrinol Metab 1972;35:857-62.

${ }^{5}$ Van Vaerenbergh P. Thijs L, Delbeke MJ, Craen M. A case of malignant hepatoma with precocious puberty. Acta Paed Belg 1972;26: 78-87.

- McArthur JW, Toll GD, Russfield AB, Beiss AM, Quinby WC, Baker WH. Sexual precocity attributable to ectopic gonadotrophin secretion by hepatoblastoma. Am J Med 1973;54:390-403.

' Kumar EV, Kumar L, Pathak IC, Dash RCJ, Joshi VV. Clinical, hormonal and untrastructural studies of a virilizing hepatoblastoma. Acta Paed Scand 1978;67:389-92.

${ }^{8}$ Flores F, Solando A, Reveil R, et al. Isosexual precocious puberty in a male infant with hepatoblastoma. Rev Invest Clin 1979;31:251-5.

- Cohn R. Right hepatic lobectomy in children. Am J Surg 1969; 118:512-76.

${ }^{10}$ Lascari AD. Vincristine therapy in an infant with probable hepatoblastoma. Pediatrics 1970;54:109-2.

Requests for reprints to: Dr $\mathbf{R}$ Beach, Department of Paediatrics, Level G, East Wing, Southampton General Hospital, Southampton SO9 4XY, England. 